\title{
Caudicicola gracilis (Polyporales, Basidiomycota), a new polypore species and genus from Finland
}

\author{
Heikki Kotiranta ${ }^{1, \star}$, Matti Kulju² \& Otto Miettinen ${ }^{3}$
}

1) Finnish Environment Institute, Natural Environment Centre, P.O. Box 140, Fl-00251 Helsinki,
Finland ( ${ }^{*}$ corresponding author's e-mail: heikki.kotiranta@ymparisto.fi)
2) Biodiversity Unit, P.O. Box 3000, Fl-90014 University of Oulu, Finland
3) Finnish Museum of Natural History, Botanical Museum, P.O. Box 7, Fl-00014 University of
Helsinki, Finland

Received 10 Jan. 2017, final version received 23 Mar. 2017, accepted 27 Mar. 2017

Kotiranta H., Kulju M. \& Miettinen O. 2017: Caudicicola gracilis (Polyporales, Basidiomycota), a new polypore species and genus from Finland. - Ann. Bot. Fennici 54: 159-167.

A new monotypic polypore genus, Caudicicola Miettinen, Kotir. \& Kulju, is described for the new species $C$. gracilis Kotir., Kulju \& Miettinen. The species was collected in central Finland from Picea abies and Pinus sylvestris stumps, where it grew on undersides of stumps and roots. Caudicicola gracilis is characterized by very fragile basidiocarps, monomitic hyphal structure with clamps, short and wide tramal cells, smooth ellipsoid spores, basidia with long sterigmata and conidiogenous areas in the margins of the basidiocarp producing verrucose, slightly thick-walled conidia. The genus belongs to the residual polyporoid clade of the Polyporales in the vicinity of Steccherinaceae, but has no known close relatives.

\section{Introduction}

The species described here was found when Heino Kulju, the brother of the second author, was making a forest road for tractors. To make way for the road, pine and spruce stumps, cut in 1997 but still relatively hard, were grubbed up. Fruiting bodies of several species of polypores were growing on the undersides of the stumps and roots, and Heino Kulju brought samples of them to his brother for identification. The lifted stumps were colonized by poroid species such as Trechispora hymenocystis, Porpomyces mucidus, Physisporinus vitreus, and such less common corticioid species as Chaetoporellus curvisporus and Jaapia ochroleuca. Fallen spruce trunks at the same site harbored species such as Meruliop- sis taxicola, Pycnoporellus fulgens and its successional predecessor Fomitopsis pinicola, and deciduous tree trunks had such seldom collected species as Athelopsis glaucina (on Salix) and Ceraceomyces violascens (on Betula).

Among the polypores collected from the underside of the stumps and their roots were also white, effused polypore specimens that the second author could not identify to any existing species, so he sent them to the first author who examined them and sent them further to the third author. Since none of the experts at the Finnish Museum of Natural History could identify them either, even to the genus, they were subjected to DNA analysis, which proved that the species was indeed unique. 


\section{Material and methods}

\section{Microscopy}

Thirty spores per specimen were measured in Cotton Blue (CB) using phase contrast illumination and oil immersion with a subjective accuracy of $0.1 \mu \mathrm{m}$ (see Miettinen et al. 2006). Other mounting media used were Melzer's reagent (IKI), Cresyl Blue (CRB) and 5\% potassium hydroxide $(\mathrm{KOH})$. The following spore and conidium dimensions are reported: $L=$ mean length, $W=$ mean width, $Q^{\prime}=$ range of the variation in length-to-width ratio, $Q=$ mean lengthto-width ratio ( $L / W$ ratio). Conidium and spore measurements (length and width) are given as the whole range (in parentheses) and $90 \%$ range excluding $5 \%$ extreme values from both ends is given outside parentheses; when both values are identical, parentheses are omitted. None of the measurements is from spore prints.

Besides the geographical co-ordinates the biological province and collecting site are indicated also according to the Finnish national uniform grid system $\left(27^{\circ} \mathrm{E}\right)$, applied to biological material by Heikinheimo and Raatikainen (1981). The nomenclature of fungi follows Kotiranta et al. (2009).

\section{Specimens examined}

Caudicicola gracilis, see type specimens cited below. Hypochnicium bombycinum. Finland. Kuusamo: Taivalkoski, Riihilehto, Populus tremula, 30 September 2004 Miettinen $9441(\mathrm{H})$. - Radulodon erikssonii. Norway. Akershus: Asker, Brønnøya S $\varnothing$, Slottsveien, Malus pumila, 28 October 2009 Hofton 09820 (O). - Spongipellis delectans. China. Liaoning: Anshan, Qianshan park, Quercus, 26 September 1998 Dai 3041 (H). - Spongipellis spumea. Finland. Uusimaa: Espoo, Träskända park, on Acer platanoides, 27 October 2005 Oksanen $100(\mathrm{H})$.

\section{DNA extraction and phylogenetic analysis}

We produced 5 new nuclear ribosomal DNA internal transcribed spacer (ITS) sequences, 5 large subunit (nLSU, 28S) sequences, 4 mitochondrial small subunit (mtSSU) sequences, 4 ATP synthase 6 (atp6) sequences, and 1 RNA
Polymerase II Largest Subunit (rpb1) sequence. They have been deposited in INSDC (Cochrane et al. 2016; see also Table 1). We also used sequences of 50 specimens retrieved from INSDC (Table 1). They were chosen based on similarity searches and the results in Miettinen et al. (2012), Binder et al. (2013) and Zhao et al. (2014). DNA was extracted using an E.Z.N.A. forensic DNA kit (Omega Bio-Tek, Norcross, GA, USA) or a DNeasy plant mini kit (Qiagen, Hilden, Germany). PCR primers included ITS1F, ITS5, ITS1, ITS4 and LR22 for ITS; CTB6, LR0R and LR7 for the partial nLSU; MS1 and MS2 for mtSSU (White et al. 1990, http:// biology.duke.edu/fungi/mycolab/primers.htm); ATP6-2 and ATP6-3 for atp6 (Krezter \& Bruns 1999), and RPB1-Af and RPB1-Cr for $r p b 1$ (Matheny et al. 2002). Sequencing primers were the same with the addition of primers LR5 and LR3R for nLSU and RPB1-Int2.2f (Binder et al. 2009) for $r p b 1$.

A concatenated data set of the residual polyporoid clade of the Polyporales was constructed containing 55 species and five loci (ITS, partial nLSU, partial mtSSU, partial $r p b 1$ and partial atp6). Phylograms were built for the concatenated data set as well as each of the loci separately. The ITS data set contained 53 species, 226 characters of which 52 parsimony informative after excluding apparently non-homologous characters from the alignment (5.8S: 156 characters, 16 parsimony informative; ITS1 + ITS2: 70 characters, 36 parsimony informative). LSU data set had 55 species, 979 characters of which 209 parsimony informative, mtSSU data set 34 species, 527 characters of which 168 parsimony informative, atp 6 data set 25 species, 633 characters of which 260 parsimony informative, $r p b 1$ data set 20 species, 1079 characters or which 383 parsimony informative, and concatenated data set 55 species, 3444 characters of which 1072 parsimony informative.

Sequences were aligned using MAFFT online version 7.244 with the strategy E-INS-I (http://mafft.cbrc.jp; Katoh \& Standley 2013) and adjusted manually using PhyDE 0.9971 (see http://phyde.de). Numbers of informative characters were calculated in MEGA6 (Tamura et al. 2013). Trees were rooted based on information from Binder et al. (2013). In the case of the con- 

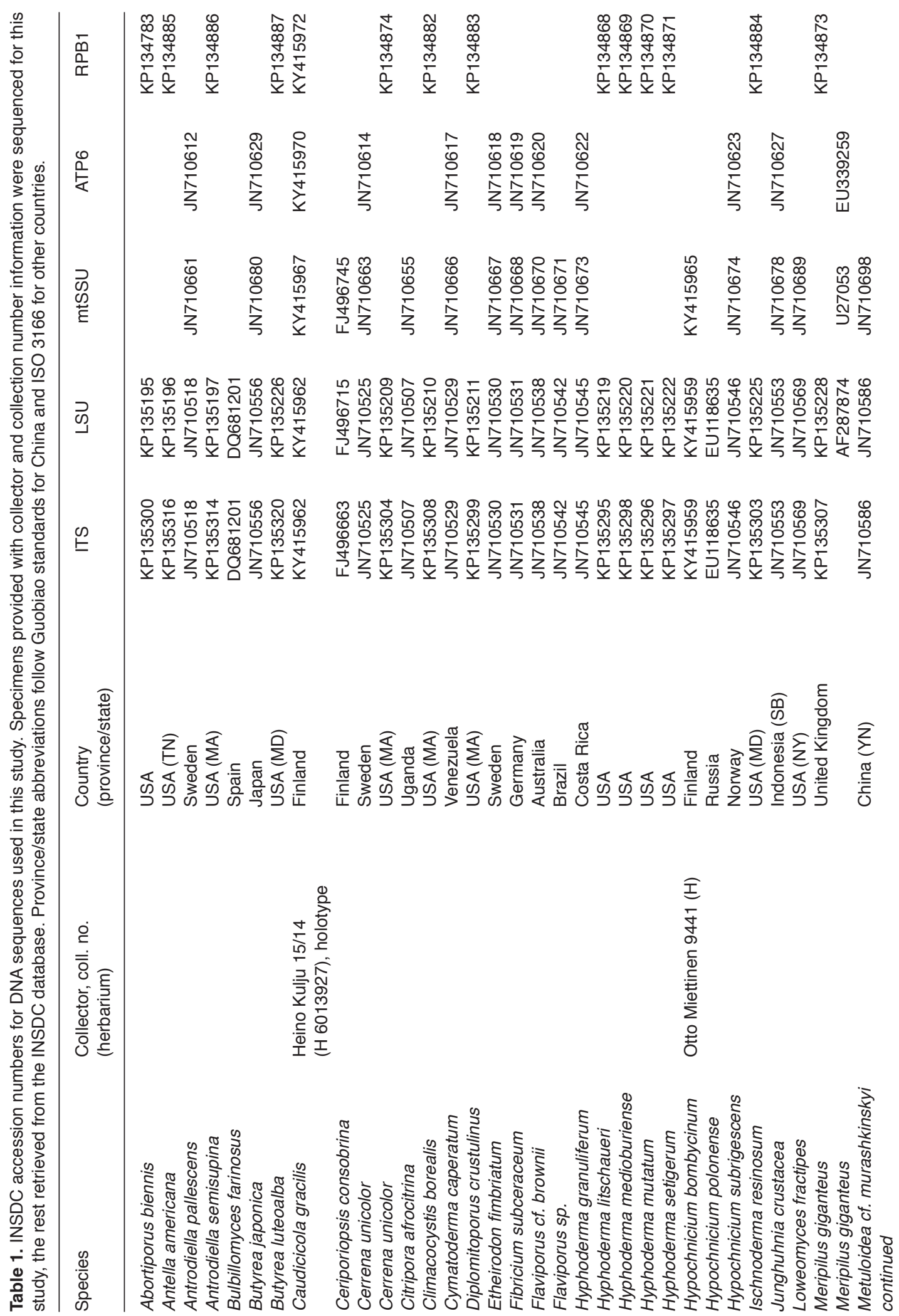


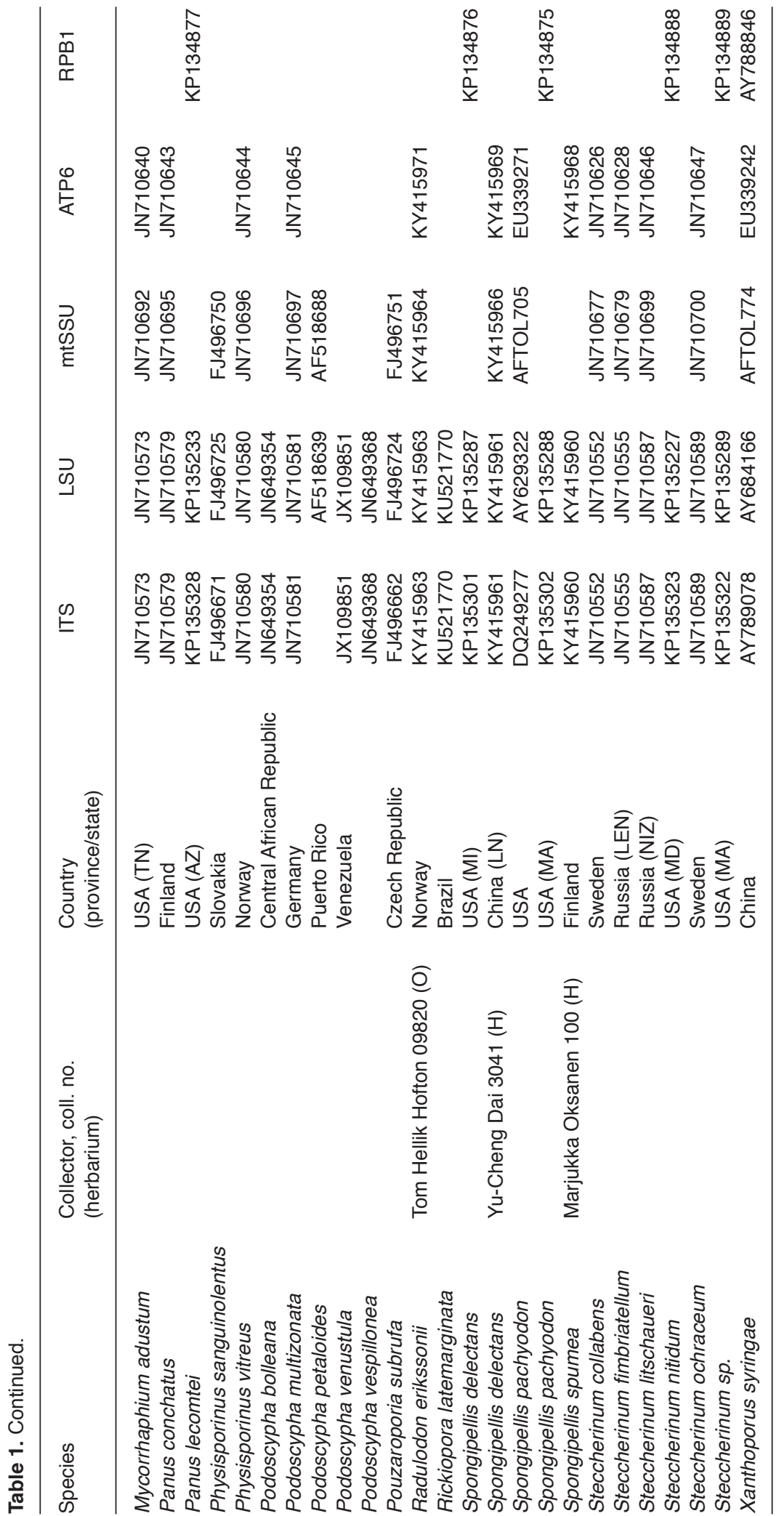


catenated, ITS, LSU and RPB1 data sets we used Ischnoderma resinosum, which is outside the residual polyporoid clade. We rooted mtSSU and atp6 data sets with Hyphoderma granuliferum since no sequence data for $I$. resinosum were available.

MrBayes 3.2 (Ronquist et al. 2012) was used for inferring Bayesian consensus trees. The LSU and $r p b 1$ data sets were partitioned as follows: ITS1 and ITS2 in one partition, 5.8S and LSU in another, and $r p b 1$ separately. The nucleotide substitution model GTR $+\mathrm{I}+\mathrm{G}$ was used for all partitions, chosen based on the AIC scoring produced in jmodeltest 2.1.6 (Darriba et al. 2012). Bayesian analyses were run with eight chains in three parallel runs, temp $=0.1$. Single-locus data sets were run for 4 million generations sampling every 2000 generations. The concatenated data set was run for 6 million generations sampling every 2500 generations. All runs converged to below 0.01 average standard deviation of split frequencies. A burn-in of $25 \%$ was used before computing the consensus tree. The alignments and phylograms are available in TreeBase (http://purl.org/ phylo/treebase/phylows/study/TB2:S20389).

\section{Results}

Our phylogenetic analyses place Caudicicola gracilis in the residual polyporoid clade. Depending on the genetic locus, Caudicicola is within Steccherinaceae (mitochondrial genes mtSSU and atp6), a sister to the rest of the Steccherinaceae $(r p b 1)$ or its position remains unresolved within the residual polyporoid clade (ITS, LSU). The concatenated data set places Caudicicola as a sister to the Steccherinaceae clade with good support (Fig. 1). For now the best family placement for Caudicicola is in Steccherinaceae, where it has no close relatives.

\section{Taxonomy}

Caudicicola Miettinen, Kotir. \& Kulju, gen. nov.

MB 819547. - Etymology: Caudicicola (Latin) from caudex $=$ stump or trunk, and cola $=$ where the fungus lives
Basidiocarp white, resupinate, very fragile, poroid, hyphal system monomitic, clamped, partly with ampullaceous-looking septa. Basidia subcylindrical with long sterigmata and born on bladder-like large cells. Spores ellipsoid, small, smooth.

\section{Caudicicola gracilis Kotir., Kulju \&} Miettinen, sp. nova (Figs. 2 and 3, Tables 2 and 3)

MB 819548. - HoLотүPE: Finland. Keski-Pohjanmaa: Pyhäjärvi, Jokikylä, Varpusuo, Picea abies dominated swampy forest, on Picea abies stump, alt. $146 \mathrm{~m}$ a.s.1., $63^{\circ} 45^{\prime} \mathrm{N}, 25^{\circ} 58^{\prime} \mathrm{E}$ (grid $27^{\circ} \mathrm{E} 707253: 344988$ ), 6 October 2014 H. Kulju 15/14 (H 6013927; isotype OULU). PARAtypes: Finland. Keski-Pohjanmaa: Pyhäjärvi, Jokikylä, Varpusuo, Picea abies dominated swampy forest, alt. 146 m a.s.1., $63^{\circ} 45^{\prime} \mathrm{N}, 25^{\circ} 58^{\prime} \mathrm{E}$ (grid $27^{\circ} \mathrm{E} 707253: 344988$ ), 18 October 2014 on Picea abies, H. Kulju 14/14 (OULU, H), on Pinus sylvestris, H. Kulju 16/14 (OULU, H), on Picea abies, H. Kulju 17/14 (OULU, H), 20 October 2014, on coniferous stump, H. Kulju 13/14 (OULU, H), 9 September 2015 on Picea abies, M. Kulju 48/15, H. Kulju \& P. Helo (OULU).

ЕтумоLOGY: gracilis $($ Latin $)=$ fragile .

Basidiocarp annual, resupinate, very fragile, pale creamish white or pale yellow when dry, total thickness up to $2.5 \mathrm{~mm}$, with a very thin white subiculum, pores angular, 3-4 per mm, after drying partly shrinking and partly widening, up to $1 \mathrm{~mm}$, with thin, partly lacerate dissepiments. Old fruit bodies have sometimes pulverulent areas at margin, which contain masses of conidia, but no rhizomorphs. No particular smell observed, taste mild. Hyphal system monomitic, hyphae relatively thin-walled, $\mathrm{CB}-$, IKI-, CRB lilac. Subiculum consists of narrow hyphal strands and loosely arranged randomly orientated hyphae (2.5)3-5 $\mu \mathrm{m}$ wide, mostly with normal clamps, but ampullaceous, up to $10 \mu \mathrm{m}$ wide septa fairly common as well as hyphae 9-11(15) $\mu \mathrm{m}$ wide; conidiogenous hyphae double walled, in some parts of subiculum common; tramal hyphae subparallel, 2.5-3.5 $\mu \mathrm{m}$ wide, clamped, with a few ampullaceous septa and vesicle-looking cells $8-15 \mu \mathrm{m}$ in diam.; dissepimental hyphae often, but not always, wide, winding, up to $9 \mu \mathrm{m}$; subhymenial hyphae mostly originate from large, often roundish cells, $8-18 \mu \mathrm{m}$ in diam., with some protuber- 


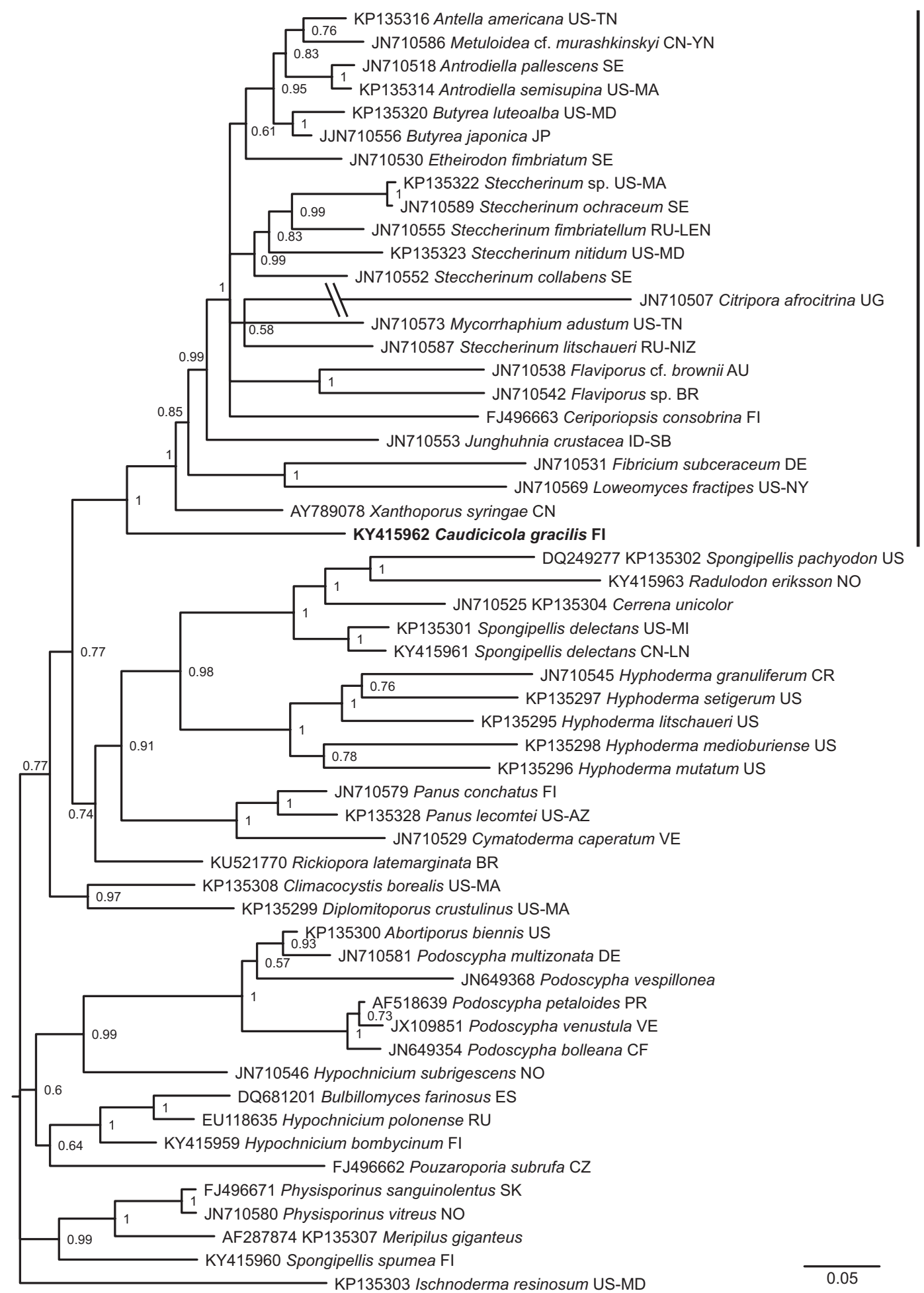

Fig. 1. Phylogeny of the residual polyporoid clade of the Polyporales. Bayesian consensus tree based on ITS, $\mathrm{nLSU}, \mathrm{mtSSU}$, atp6 and rpb1 sequences. Numbers denote posterior probabilities. 

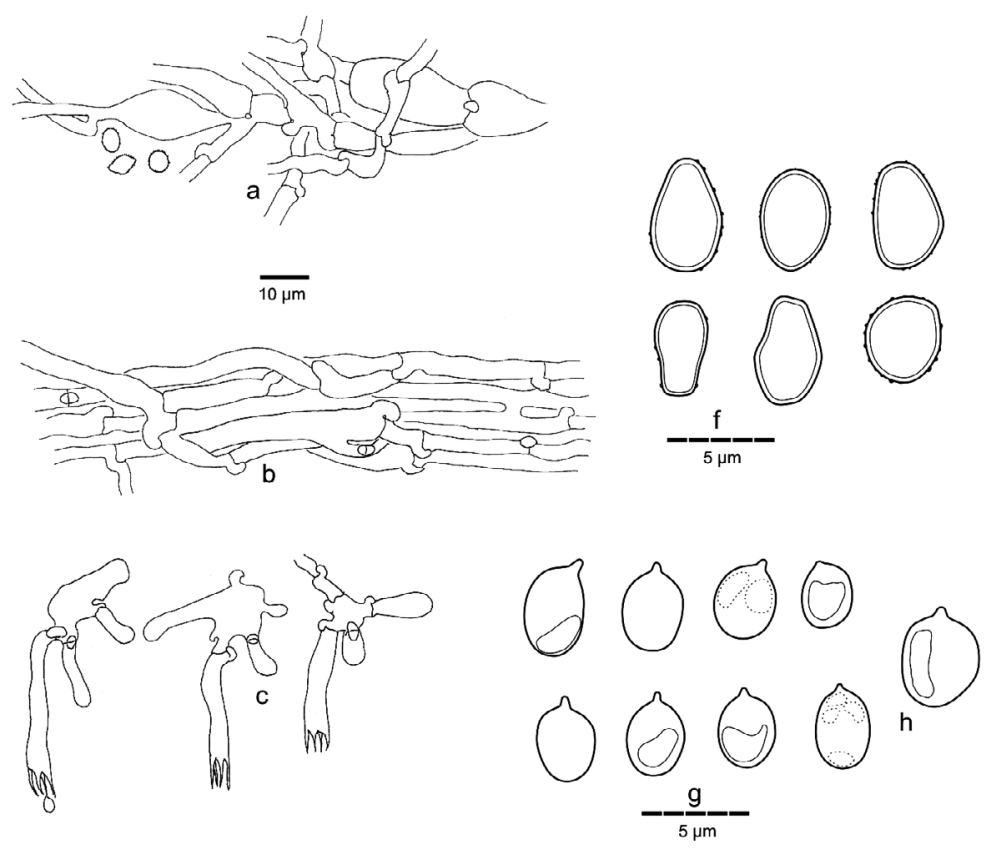
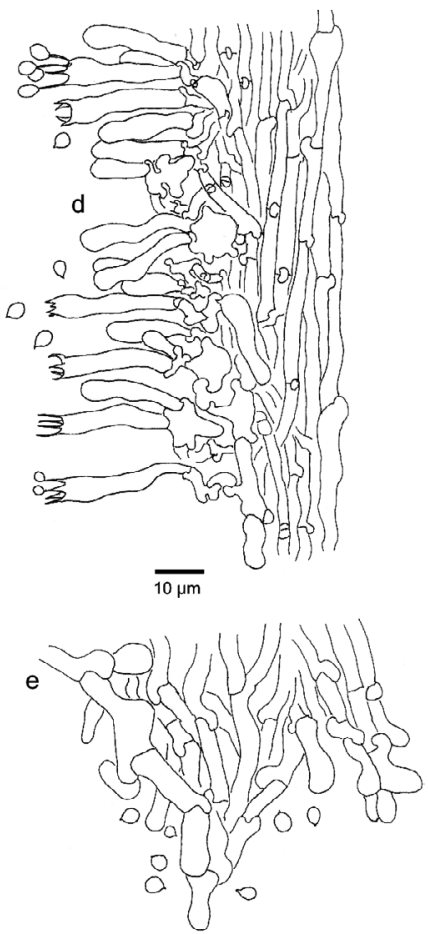

Fig. 2. Microscopy of Caudicicola gracilis. - a: Subicular hyphae with ampullaceous septa, wide hyphae and conidia. - b: Subicular strand with ampullaceous septa. - c: Bladder-like cells which give rise to basidioles and basidia. - d: Section trough trama and hymenium showing the bladder-like cells in subhymenium, basidia and spores. - e: Dissepiment edge with wide hyphae. - f: Conidia. - g: Basidiospores (from the holotype).

ances, thin-walled, richly clamped and branched, 2-3 $\mu \mathrm{m}$ wide. Cystidia and cystidioles absent. Hymenial cells with inclusion that stains in IKI and $\mathrm{CB}$, gloeocystidia-looking. Basidia basally clamped (normally), subcylindrical, (15)20$28 \times 4.5-5 \mu \mathrm{m}$, with (2) 4 sterigmata, which are exceptionally long, typically $5 \mu \mathrm{m}$ but even up to $8 \mu \mathrm{m}$. Spores smooth, subglobose, broadly ellipsoid or pip-shaped, fairly thin-walled, with a relatively large apiculus, commonly with one or many shiny, irregular bodies inside, $\mathrm{CB}-$, IKI-, 3.0-4.1(4.5) $\times(2.1) 2.3-3.1(3.6) \mu \mathrm{m}, L$ $=3.50 \mu \mathrm{m}, W=2.69 \mu \mathrm{m}$; conidia ellipsoid, often broadly fusiform, reminding a protozoan

Table 2. Spore dimensions of the studied Caudicicola gracilis specimens. $L=$ mean length, $W=$ mean width, $Q^{\prime}=$ range of the variation in length-to-width ratio, $Q=$ mean length-to-width ratio ( $L / W$ ratio), $n=$ number of measured spores. Length and width are given as the whole range (in parentheses) and $90 \%$ range excluding $5 \%$ extreme values from both ends is given outside parentheses; when both values are identical, parentheses are omitted.

\begin{tabular}{|c|c|c|c|c|c|c|c|}
\hline & Length & $L$ & Width & $W$ & $Q^{\prime}$ & $Q$ & $n$ \\
\hline Caudicicola gracilis & $3.0-4.1(4.5)$ & 3.50 & (2.1)2.3-3.1(3.6) & 2.69 & $1.1-1.5(1.7)$ & 1.30 & $211^{*}$ \\
\hline Holotype & (3.0)3.1-4.2 & 3.54 & (2.2)2.4-3.0(3.2) & 2.78 & $1.1-1.5(1.6)$ & 1.28 & 61 \\
\hline H. Kulju 13/14 & $3.0-4.0(4.3)$ & 3.44 & $2.2-2.8(2.9)$ & 2.50 & (1.1)1.2-1.7 & 1.38 & 30 \\
\hline H. Kulju 14/14 & $3.0-4.0(4.2)$ & 3.64 & $(2.1) 2.2-3.4(3.5)$ & 2.70 & $1.1-1.7$ & 1.35 & 30 \\
\hline H. Kulju 16/14 & (3.4)3.5-4.2(4.5) & 3.81 & $2.5-3.4(3.6)$ & 2.87 & $1.1-1.5$ & 1.32 & 30 \\
\hline H. Kulju $17 / 14$ & $3.0-3.6(3.7)$ & 3.30 & $(2.2) 2.3-2.8(3.0)$ & 2.55 & $1.1-1.5$ & 1.29 & 30 \\
\hline M. Kulju 48/15 & $3.0-3.8(4.0)$ & 3.21 & (2.2)2.3-3.0(3.1) & 2.65 & $1.1-1.4(1.6)$ & 1.21 & 30 \\
\hline
\end{tabular}

* from all specimens listed below. 


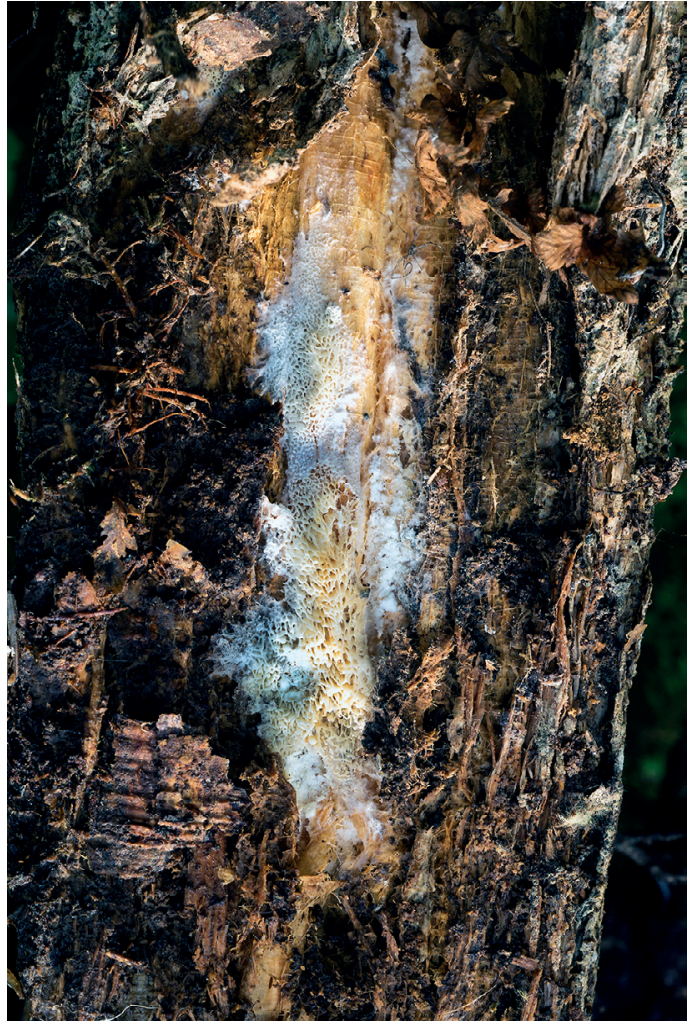

Fig. 3. Mature basidiome of Caudicicola gracilis on Picea abies stump. Photographed in situ by Pekka Helo. Specimen Kulju, M. 48/15, Kulju, H. \& Helo, $P$ (OULU).

ciliate, slightly thick-walled, finely ornamented or more rarely smooth, $\mathrm{CB}+$, IKI-, (4.0)4.5$7.0(8.0) \times(2.7) 3.0-4.5(5.2) \mu \mathrm{m}, L=5.44 \mu \mathrm{m}$, $W=3.60 \mu \mathrm{m}$.

Habitat ECOLOGY AND Distribution: Found only in one location in central Finland. Its habitat was a boreal wooded, drained minerotrophic mire. The dominant tree species was spruce (Picea abies) intermixed with pine (Pinus sylvestris), birches (Betula spp.) and some willows (Salix spp.). The site was selectively cut about 20 years earlier, but has otherwise no intensive forest management history. The ground vegetation consists of mosses, Dryopteris carthusiana and Equisetum sylvaticum, and in dryer places of Vaccinium vitis-idaea. Basidiocarps grew on the underside of spruce and pine stumps and their roots, so basically underground. Caudicicola gracilis is apparently a wood- or litter decomposer, since there are no mycorrhizal species in Steccherinaceae or in Polyporales (Hibbett et al. 2014).

The basidiocarps of $C$. gracilis mostly resemble those of Trechispora hymenocystis, which, however, has normally hyphal cords at the margins (see Niemelä 2016: 374). Also Anomoporia kamtschatica is very similar looking in being white and fragile. Oligoporus sericeomollis is as well relatively similar even if not so fragile, and when fresh, it has a strong pungent smell and the taste is very bitter.

Microscopically the ampullaceous septa, especially in subicular cords, resembles those of Porpomyces mucidus and many Trechispora species, whereas the subcylindrical basidia are almost like those in the genus Ceraceomyces. If the ampullate septa are really homologous with the similar looking septa in e.g. Trechispora is not confirmed. Small spores are often pip-shaped and many have the shape of the spores of Sistotrema muscicola. The number of conidia varies; in some specimens they are few, in some others quite numerous and the shape varies from ellipsoid to broadly fusiform and in rare cases some

Table 3. Conidium dimensions of the studied Caudicicola gracilis specimens. $L=$ mean length, $W=$ mean width, $Q$ ' $=$ range of the variation in length-to-width ratio, $Q=$ mean length-to-width ratio ( $L / W$ ratio), $n=$ number of measured conidia. Length and width are given as the whole range (in parentheses) and $90 \%$ range excluding $5 \%$ extreme values from both ends is given outside parentheses; when both values are identical, parentheses are omitted.

\begin{tabular}{lccccccc}
\hline & Length & $L$ & Width & $W$ & $Q^{\prime}$ & $Q$ \\
\hline Caudicicola gracilis & $(4.0) 4.5-7.0(8.0)$ & 5.44 & $(2.7) 3.0-4.5(5.2)$ & 3.60 & $(1.1) 1.2-1.9(2.1)$ & 1.51 & $130^{*}$ \\
Holotype & $(4.3) 4.5-7.1(8.0)$ & 6.03 & $(2.7) 3.3-5.0(5.2)$ & 4.04 & $(1.1) 1.2-1.9(2.0)$ & 1.49 & 40 \\
H. Kulju 14/14 & $(4.4) 4.5-5.7$ & 4.94 & $(2.8) 3.0-4.0(4.5)$ & 3.31 & $(1.1) 1.3-1.8(1.9)$ & 1.49 & 30 \\
H. Kulju 17/14 & $5.0-7.0(7.5)$ & 5.65 & $3.0-3.8(4.0)$ & 3.47 & $(1.3) 1.4-2.0(2.1)$ & 1.63 & 30 \\
M. Kulju 48/15 & $(4.0) 4.3-5.3(5.5)$ & 4.95 & $3.1-3.9(4.0)$ & 3.42 & $1.2-1.6(1.7)$ & 1.45 & 30 \\
\hline
\end{tabular}

\footnotetext{
* from all specimens listed below.
} 
are almost like in Trechispora stevensonii (see Bernicchia \& Gorjón 2010: 681). For the mode of formation of conidia of $C$. gracilis see Kirk et al. (2008: 32, fig. 22).

The combination of characteristics, a resupinate, very fragile basidiocarp, monomitic hyphal system with ampullaceous septa, subcylindrical basidia which arise from bladder-like cells and small pip-shaped spores plus smooth or rough conidia is unique, and we do not know any other species microscopically resembling $C$. gracilis. The closest relatives of Caudicicola in the Steccherinaceae do not resemble it morphologically, though many of them are soil inhabiting or rootrotting such as Caudicicola may be (e.g. Xanthoporus syringae, Tyromyces wynnae, Loweomyces fractipes).

All the basidiocarps grew on undersides of spruce or pine stumps and could be seen only after the stumps were lifted from the ground. If this is a typical growth habit of this species, then it is no wonder that $C$. gracilis has never before been found during extensive polypore inventories carried out in Finnish old-growth forests. It may be more common than a single known location suggests.

\section{Acknowledgements}

Heino Kulju (Pyhäjärvi) is warmly thanked for lending us his specimens. Teuvo Ahti (Helsinki) advised us on Latin, and Pekka Helo gave his excellent photo at our disposal and is cordially thanked. Karl-Henrik Larsson (Oslo) provided us with the sequences of Radulodon erikssonii.

\section{References}

Bernicchia A. \& Gorjón S.P. 2010: Corticiaceae s.1. - Fungi Europaei 12: 1-1008.

Binder M., Justo A., Riley R., Salamov A., Lopez-Giraldez F., Sjökvist E., Copeland A., Foster B., Sun H., Larsson E., Larsson K.-H., Townsend J., Grigoriev I.V. \& Hibbett D.S. 2013: Phylogenetic and phylogenomic overview of the Polyporales. - Mycologia 105: 1350-1373.

Binder M., Larsson K.-H., Matheny P.B. \& Hibbett D.S. 2009: Amylocorticiales ord. nov. and Jaapiales ord. nov.: Early diverging clades of Agaricomycetidae dominated by corticioid forms. - Mycologia 102: 865-880.

Cochrane G., Karsch-Mizrachi I. \& Takagi T. \& INSDC. 2016: The international nucleotide sequence database collaboration. - Nucleic Acids Res. 44(D1): D48-D50, doi:10.1093/nar/gkv1323.

Darriba D., Taboada G.L., Doallo R. \& Posada D. 2012: jModelTest 2: more models, new heuristics and parallel computing. - Nature Methods 9(8): 772, doi:10.1038/ nmeth.2109.

Heikinheimo O. \& Raatikainen M. 1981: Ruutukoordinaattien ja paikannimien käyttö Suomessa [Grid references and names of localities in recording of biological finds in Finland]. - Notul. Entomol. 61: 133-154. [In Finnish, with English summary].

Hibbett D.S., Bauer R., Binder M., Giachini A.J., Hosaka K., Justo A., Larsson E., Larsson K.-H., Lawrey J.D., Miettinen O., Nagy L.G., Nilsson R.H., Weiss M. \& Thorn R.G. 2014: Agaricomycetes. - In: McLaughlin D.J. \& Spatafora J.W. (eds.), Systematics and evolution: 373-429. Springer, Berlin \& Heidelberg.

Katoh K. \& Standley D.M. 2013: MAFFT multiple sequence alignment software version 7: improvements in performance and usability. - Mol. Biol. Evol. 30: 772-780.

Kirk P.M., Cannon P.F., Minter D.W. \& Stalpers J.A. 2008: Dictionary of the fungi, 10th ed. - CAB International, Cromwell Press, Trowbridge.

Kotiranta H., Saarenoksa R. \& Kytövuori I. 2009: Aphyllophoroid fungi of Finland. A check-list with ecology, distribution, and threat categories. - Norrlinia 19: 1-223.

Kretzer A.M. \& Bruns T.D. 1999: Use of atp6 in Fungal Phylogenetics, an example from the Boletales. - Mol. Phyl. Ecol. 13: 483-492.

Matheny P.B., Liu Y.J., Ammirati J.F. \& Hall B.D. 2002: Using RPB1 sequences to improve phylogenetic inference among mushrooms (Inocybe, Agaricales). - Am. J. Bot. 89: 688-698.

Miettinen O., Niemelä T. \& Spirin W. 2006: Northern Antrodiella species: the identity of A. semisupina, and type studies of related taxa. - Mycotaxon 96: 211-239.

Miettinen O., Larsson E., Sjökvist E. \& Larsson K.-H. 2012: Comprehensive taxon sampling reveals unaccounted diversity and morphological plasticity in a group of dimitic polypores (Polyporales, Basidiomycota). - Cladistics 28: 251-270.

Niemelä T. 2016: The polypores of Finland. - Norrlinia 31: 1-430. [In Finnish, with English summary].

Ronquist F., Teslenko M., van der Mark P., Ayres D.L., Darling A., Höhna S., Larget B., Liu L., Suchard M.A. \& Huelsenbeck J.P. 2012: MrBayes 3.2: efficient Bayesian phylogenetic inference and model choice across a large model space. - Syst. Biol. 61: 539-542.

Tamura K., Stecher G., Peterson D., Filipski A. \& Kumar S. 2013: MEGA6: molecular evolutionary genetics analysis version 6.0. - Mol. Biol. Evol. 30: 2725-2729.

White T.J., Bruns T., Lee S. \& Taylor J.W. 1990: Amplification and direct sequencing of fungal ribosomal RNA genes for phylogenetics. - In: Innis M.A., Gelfand D.H., Sinisky J.J. \& White T.J. (eds.), PCR protocols, a guide to method and application: 315-322. Academic Press, San Diego.

Zhao C.-L., Cui B.-K., Song J. \& Dai Y.-C. 2014: Fragiliporiaceae, a new family of Polyporales (Basidiomycota). - Fungal Diversity 70: 115-126. 